\title{
Effects of DA-6 on Phosphorus and Potassium Uptakes of Tomato Seedlings under Cadmium Stress
}

\author{
Shiyao Shan ${ }^{1}$, Wanjia Tang ${ }^{2}$, Xuemei Peng ${ }^{2}$, Jing $\mathrm{Lu}^{2}$, Han $\mathrm{Liu}^{2}$, and Huanxiu $\mathrm{Li}^{1, *}$ \\ ${ }^{1}$ Institute of Pomology and Olericulture, Sichuan Agricultural University, Chengdu 611130, China \\ ${ }^{2}$ College of Horticulture, Sichuan Agricultural University, Chengdu 611130, China
}

\begin{abstract}
In order to study the effect of foliar DA-6 on the phosphorus and potassium content of tomato seedlings under cadmium stress, the pot experiment was used to cultivate 'Zhongza 9' tomato in $50 \mu \mathrm{mol} / \mathrm{L}$ $\mathrm{CdCl}_{2} \cdot 2.5 \mathrm{H}_{2} \mathrm{O}$ nutrient solution. The effects of DA- 6 at different concentrations $(0,10,20,30$ and $40 \mathrm{mg} / \mathrm{L})$ on the phosphorus and potassium uptakes of tomato seedlings under cadmium stress were studied. The results showed that when the DA-6 concentration was $20 \mathrm{mg} / \mathrm{L}$, the phosphorus content in the root and stem of tomato seedlings increased significantly, which were $41.5 \%$ and $12.8 \%$ higher than the control. In all treatments, when the DA-6 concentration was $10 \mathrm{mg} / \mathrm{L}$, the potassium content of tomato seedling roots, stems and shoots increased significantly, which were $25.4 \%, 10.0 \%$, and $5.8 \%$ higher than the control. In summary, the low-concentration DA-6 treatment had a certain effect on increasing the phosphorus and potassium content of tomato, and there were differences in the optimal concentration of phosphorus and potassium content.
\end{abstract}

\section{Introduction}

Soil is the foundation of human survival, but with the rapid development of industry and agriculture, the problem of soil heavy metal pollution has become increasingly prominent, of which the problem of cadmium pollution is particularly serious [1-2]. Cadmium is extremely toxic and easily accumulates in the soil for a long time [3]. Soil cadmium pollution has two negative effects on crops. First, the growth of the crop is not inhibited, but its edible part of the cadmium content exceeds the standard, which seriously affects human health. Second, crop growth is severely suppressed or even unable to grow [4]. When plants are enriched with a certain level of cadmium, they are susceptible to symptoms such as growth retardation, leaf atrophy, and yield decline [5-7]. Therefore, it is necessary to adopt some agronomic measures to reduce the toxicity of cadmium pollution.

Agronomic measures can be used to promote plant growth and nutrient absorption, such as plant hormones (including cytokinin), hybridisation, grafting and so on [8-11]. Diethyl aminoethyl hexanoate (DA-6) is a new type of cytokinin-type plant growth regulator [12], which has various functions such as auxin, gibberellin and cytokinin. Studies have shown that low-concentration DA-6 can regulate, control and promote the growth of many plants, can promote carbohydrate metabolism and material accumulation, significantly increase yield, and can improve crop quality [13-14]. At the same time, DA6 can promote plant cell division, elongation, and $C$ and $\mathrm{N}$ metabolism [15]. Studies had confirmed that DA-6 could significantly promote the growth of soybean, corn, and cucumber root systems, and increase the root vitality of corn, which was conducive to increasing the depth of the root system and promoting the vertical growth of the root system [16-18]. Plant growth regulators have the ability to enhance the plant's ability to enrich soil heavy metals. Studies had shown that DA-6 at a certain concentration could increase the $\mathrm{Cd}$ content in root and shoot of ryegrass (Lolium perenne L.) and promoted the enrichment of $\mathrm{Cd}$ by ryegrass [19]. DA-6 can be naturally degraded in the natural world, without toxicity, no residue, and does not contain any hormones. It has the characteristics of safety, high efficiency, low price and easy use, so it has broad application prospects and market value [14].

Tomato (Solanum Lycopersicon L.) is an annual or perennial herb of Solanum in Solanaceae, which has a large amount of growth and demand for mineral elements. It is rich in vitamin $\mathrm{A}$, vitamin $\mathrm{C}$, vitamin $\mathrm{E}$ and lycopene. It is an important vegetable widely cultivated all over the world and occupies an important position in the annual supply of vegetables [20]. Tomato has weak resistance to cadmium contaminated soil. Its fruit has a long harvest period and high yield, and it will consume a lot of soil nutrients and need sufficient nutrient supply. Therefore, an adequate supply of phosphorus and potassium is a necessary factor to ensure the normal growth and development of processed tomatoes and increase the phosphorus and potassium content [21].

In view of this, in order to further improve the resistance of tomatoes to cadmium-contaminated soil,

\footnotetext{
* Corresponding author: 479942014@qq.com
} 
DA-6 was sprayed onto tomato seedlings to study the effect of foliar DA-6 on the distribution of phosphorus and potassium content in tomato seedlings under cadmium treatment to provide a reference for plants to improve plant ability to resist cadmium pollution.

\section{Materials and Method}

\subsection{Plant materials}

'Zhongza No. 9' tomato was used as a plant material, which belonged to hybrids and was purchased from China Vegetable Agricultural Technology (Beijing) limited company.

\subsection{Experimental design}

The pot experiment was conducted at Institute of Pomology and Olericulture of Sichuan Agricultural University from September 2019 to November 2019. In September, evenly sized tomato seeds were sterilized in $10 \% \mathrm{H}_{2} \mathrm{O}_{2}(\mathrm{v} / \mathrm{v})$ for $10 \mathrm{~min}$, and then rinsed with ultrapure water. The sterilized seeds were evenly placed in a petri dish lined with wet filter paper, and germinated in an artificial incubator at $20^{\circ} \mathrm{C}$. When the radicle length was $5 \mathrm{~mm}$, the seeds were sown in seedling trays and grown in the artificial incubator. The artificial incubator conditions were a light intensity of $200 \mu \mathrm{mol} / \mathrm{m}^{2} / \mathrm{s}^{1}$, the temperature of $23^{\circ} \mathrm{C} / 18^{\circ} \mathrm{C}$ (day/night), and a photoperiod of $12 \mathrm{~h} / 12 \mathrm{~h}$ (day/night).

After 15 days of cultivation, when 3-4 euphyllas were unfolded, selecting healthy and uniform tomato seedlings transplanted them into a nutrition bowl filled with perlite (12 $\mathrm{cm}$ in diameter and height). In order to prevent the loss of cadmium penetration, the nutrition bowl was placed in a plastic tray. After transplantation, the culture conditions were $50 \mu \mathrm{mol} / \mathrm{L} \quad \mathrm{CdCl}_{2} \cdot 2.5 \mathrm{H}_{2} \mathrm{O}$ nutrient solution in Hoagland solution, and the nutrient solution was changed every 2 days ( $1 \mathrm{~L}$ each time). The leaves of Cd-treated tomato seedlings were sprayed with different concentrations of DA-6 solution at 9 am $(0,10,20,30$, and $40 \mathrm{mg} / \mathrm{L}$ ), and the control was sprayed with distilled water only (CK). DA-6 was sprayed to tomato seedlings every 15 days, and each treatment was sprayed with 40 $\mathrm{mL}$, and sprayed twice. Each treatment consisted of 4 pots, 1 plant per pot, for a total of 4 replicates (in a plastic tray). All tomato seedlings were placed in an artificial culture room at a temperature of $22^{\circ} \mathrm{C} / 16^{\circ} \mathrm{C}$ (day/night) and a photoperiod of $12 \mathrm{~h} / 12 \mathrm{~h}$. To avoid marginal effects, the positions of the pallets were exchanged regularly.

\subsection{Project determination}

After the tomato seedlings had grown for 30 days, the whole plant was harvested. Root and shoot were washed with distilled water, and then washed with deionized water 3 times. The plant's root, stem, and leaf were divided into packs, killed at $105{ }^{\circ} \mathrm{C}$ for $15 \mathrm{~min}$, dried at $75^{\circ} \mathrm{C}$ to constant weight, crushed, and passed through a 100-mesh sieve. The content of potassium was determined by a flame spectrophotometer, and the content of phosphorus was determined by a molybdenum antimony colorimetric method [22].

\subsection{Statistical analysis}

Statistical analysis was performed on the test data by using Excel 2010, and the data was subjected to significant analysis by using SPSS20.0 software (LSD method).

\section{Results}

\subsection{Effects of different concentrations of DA-6 on phosphorus content of tomato seedlings}

As can be seen from Table 1, in terms of the phosphorus content of tomato seedlings, DA-6 treatments with different concentrations differed. With the increase of treatment concentration, the phosphorus content of each part increased first and then decreased. Among them, the treatment of $20 \mathrm{mg} / \mathrm{L} \mathrm{DA}-6$ had the best effect, which had a significant effect on the phosphorus content of tomato seedlings, and promoted the increase of root and stem phosphorus content. When treated with $20 \mathrm{mg} / \mathrm{L}$ DA-6, the phosphorus content in roots and stems was $0.358 \mathrm{mg} / \mathrm{g}$ and $0.299 \mathrm{mg} / \mathrm{g}$, which were $41.5 \%$ and $12.8 \%$ higher than those in the control treatment, with significant differences $(P<0.05)$. When the treatment concentration was $10 \mathrm{mg} / \mathrm{L}$ and $30 \mathrm{mg} / \mathrm{L}$, the phosphorus content of tomato seedlings had an increasing trend compared with the treatment, but the difference was not significant. Phosphorus content in leaf and shoot was not significantly different from the control after treatment with different concentrations of DA-6, and decreased when treated with $40 \mathrm{mg} / \mathrm{L} \mathrm{DA}-6$.

\subsection{Effects of different concentrations of DA-6 on potassium content of tomato seedlings}

As can be seen from Table 2, in terms of the potassium content of tomato seedlings, there were differences between different concentrations of DA- 6 treatment. The treatment with $10 \mathrm{mg} / \mathrm{L} \mathrm{DA}-6$ had the best effect and had the significant potassium content on tomato seedlings, promoted the inctrease of potassium content in root, stem and shoot, which were $2.519 \mathrm{mg} / \mathrm{g}, 3.079 \mathrm{mg} / \mathrm{g}$ and $3.340 \mathrm{mg} / \mathrm{g}$, respectively, and higher than those of the control treatment by $25.4 \%, 10.0 \%$ and $5.8 \%$, respectively. When the treatment concentration reached $20 \mathrm{mg} / \mathrm{L}$, the potassium content of tomato seedlings began to decrease, and the potassium content of stems, leave and shoot decreased significantly compared with the control. As the treatment concentration increased, the potassium content of each part decreased significantly. At $40 \mathrm{mg} / \mathrm{L}$ treatment, root, stem, leaf and shoot were $1.660 \mathrm{mg} / \mathrm{g}, 2.079 \mathrm{mg} / \mathrm{g}, 1.787 \mathrm{mg} / \mathrm{g}$, and $1.901 \mathrm{mg} / \mathrm{g}$, which were $17.5 \%, 42.5 \%, 36.8 \%$, and $39.8 \%$ lower than 
the control treatment, respectively, with significant differences $(P<0.05)$.

Table 1. Effects of different concentrations of DA-6 on phosphorus content of tomato seedlings.

\begin{tabular}{|c|c|c|c|c|}
\hline $\begin{array}{c}\text { Treatments } \\
(\mathbf{m g} / \mathbf{L})\end{array}$ & $\begin{array}{c}\text { Root } \\
(\mathbf{m g} / \mathbf{g})\end{array}$ & $\begin{array}{c}\text { Stem } \\
(\mathbf{m g} / \mathbf{g})\end{array}$ & $\begin{array}{c}\text { Leaf } \\
(\mathbf{m g} / \mathbf{g})\end{array}$ & $\begin{array}{c}\text { Shoot } \\
(\mathbf{m g} / \mathbf{g})\end{array}$ \\
\hline 0 & $0.253 \pm 0.012 \mathrm{bc}$ & $0.265 \pm 0.009 \mathrm{c}$ & $0.360 \pm 0.013 \mathrm{a}$ & $0.320 \pm 0.010 \mathrm{a}$ \\
\hline 10 & $0.264 \pm 0.011 \mathrm{bc}$ & $0.276 \pm 0.004 \mathrm{bc}$ & $0.362 \pm 0.016 \mathrm{a}$ & $0.324 \pm 0.010 \mathrm{a}$ \\
\hline 20 & $0.358 \pm 0.014 \mathrm{a}$ & $0.299 \pm 0.015 \mathrm{a}$ & $0.367 \pm 0.012 \mathrm{a}$ & $0.339 \pm 0.010 \mathrm{a}$ \\
\hline 30 & $0.259 \pm 0.007 \mathrm{bc}$ & $0.290 \pm 0.015 \mathrm{ab}$ & $0.372 \pm 0.009 \mathrm{a}$ & $0.335 \pm 0.011 \mathrm{a}$ \\
\hline 40 & $0.242 \pm 0.009 \mathrm{c}$ & $0.236 \pm 0.005 \mathrm{~d}$ & $0.291 \pm 0.012 \mathrm{~b}$ & $0.270 \pm 0.007 \mathrm{~b}$ \\
\hline
\end{tabular}

Values are means $( \pm \mathrm{SE})$ of four replicate pots. Different lowercase letters within a column indicate significant differences based on one-way analysis of variance in SPSS 20.0 followed by the least significant differences at the $5 \%$ confidence level.

Table 2. Effects of different concentrations of DA-6 on potassium content of tomato seedlings.

\begin{tabular}{|c|c|c|c|c|}
\hline $\begin{array}{c}\text { Treatments } \\
(\mathbf{m g} / \mathbf{L})\end{array}$ & $\begin{array}{c}\text { Root } \\
(\mathbf{m g} / \mathbf{g})\end{array}$ & $\begin{array}{c}\text { Stem } \\
(\mathbf{m g} / \mathbf{g})\end{array}$ & $\begin{array}{c}\text { Leaf } \\
(\mathbf{m g} / \mathbf{g})\end{array}$ & $\begin{array}{c}\text { Shoot } \\
(\mathbf{m g} / \mathbf{g})\end{array}$ \\
\hline 0 & $2.009 \pm 0.102 \mathrm{~b}$ & $3.616 \pm 0.025 \mathrm{~b}$ & $2.827 \pm 0.078 \mathrm{a}$ & $3.157 \pm 0.045 \mathrm{~b}$ \\
\hline 10 & $2.519 \pm 0.090 \mathrm{a}$ & $3.979 \pm 0.116 \mathrm{a}$ & $2.839 \pm 0.130 \mathrm{a}$ & $3.340 \pm 0.127 \mathrm{a}$ \\
\hline 20 & $1.945 \pm 0.057 \mathrm{bc}$ & $2.536 \pm 0.117 \mathrm{c}$ & $2.022 \pm 0.129 \mathrm{~b}$ & $2.238 \pm 0.037 \mathrm{c}$ \\
\hline 30 & $1.805 \pm 0.090 \mathrm{~cd}$ & $2.204 \pm 0.104 \mathrm{~d}$ & $1.828 \pm 0.170 \mathrm{~b}$ & $2.000 \pm 0.061 \mathrm{~d}$ \\
\hline 40 & $1.660 \pm 0.092 \mathrm{~d}$ & $2.079 \pm 0.041 \mathrm{~d}$ & $1.787 \pm 0.106 \mathrm{~b}$ & $1.901 \pm 0.061 \mathrm{~d}$ \\
\hline
\end{tabular}

Values are means $( \pm \mathrm{SE})$ of four replicate pots. Different lowercase letters within a column indicate significant differences based on one-way analysis of variance in SPSS 20.0 followed by the least significant differences at the $5 \%$ confidence level.

\section{Discussion and conclusions}

Tomato is a sensitive crop of soil cadmium. When it exceeds $8 \mathrm{mg} / \mathrm{kg}$, the chlorophyll a, chlorophyll b, net photosynthetic rate, the transpiration rate, stomatal conductance, intercellular $\mathrm{CO}_{2}$ concentration, and so on change significantly, thus affecting the growth of tomato grows [23].

Phosphorus as a substrate or regulator directly participates in all aspects of photosynthesis, including absorption of light energy, formation of assimilation forces, Calvin cycle, and transportation of assimilation products [24]. Potassium is closely related to photosynthesis of plants, and it can promote the transport of photosynthetic products mainly from the phloem to the physiological response reservoir in the form of sucrose and amino acids [25].

Studies have shown that spraying DA-6 in tomato seedlings has a certain effect on stimulating growth [26]. In this experiment, low concentration of DA-6 treatment could effectively increase the phosphorus content in tomato root and stem. High concentration of DA-6 treatment could reduce the phosphorus content in tomato organs. When treated with $20 \mathrm{mg} / \mathrm{L}$ DA-6, the phosphorus content of tomato seedlings had a significant effect, and the phosphorus content in root and stem increased significantly. For potassium content, compared with the control, the potassium content of tomato seedling root, stem and shoot significantly increased when treated with $10 \mathrm{mg} / \mathrm{L}$ DA-6. When treated with 40 $\mathrm{mg} / \mathrm{L}$, the potassium content in root, stem, leaf and shoot decreased significantly compared with the control.

In summary, low-concentration DA-6 treatment had a certain effect on improving the phosphorus and potassium content of tomato. When sprayed at a concentration of $20 \mathrm{mg} / \mathrm{L}$, DA-6 significantly increased the phosphorus content in root and stem of tomato seedlings. When DA- 6 concentration was $10 \mathrm{mg} / \mathrm{L}$, the potassium content in root, stem and shoot had a significant effect.

\section{Acknowledgements}

We thank Teacher Tang and Teacher Lin. At the same time, we thank the College of Horticulture of Sichuan Agricultural University for their support. 


\section{References}

1. Yi, Y.L., Wang, Y., Zhang, D.G., Guo, L.L., Qi, X. (2010) Analysis on distribution and migration characteristics of $\mathrm{Pb}$ and $\mathrm{Cd}$ in soil, plant and dust fall in Urban region of Shenyang city. Chin. J. Soil Sci., 41: 1466-1470.

2. Zhang, L.K., Li, H.P., Huang, X.M., Li, Y.M., Jiao, K.M., Sun, P., Wang, W.D. (2016) Soil heavy metal spatial distrution and source analysis around an aluminum plant in Baotou. Chin. J. Envir. Sci., 37: 1139-1146.

3. Chen, L., Song, Y.F., Zhang, W., Li, X.Y., Wang, L., Ji, P.H., Yang, X.X. (2008) Assessment of toxicity effects for cadmium contamination in soils by means of multi-indexes. Chin. J. Envir. Sci. 29, 2606-2612.

4. Du, R.Y., Nei, C.R., Lin, C.X., Liu, Y. (2006) Effects of soil cadmium on the growth of two potential energy plants. Ecol. Environ., 2006, 15: 735-738.

5. Zhang, J.B., Huang, W.N. (2000) Advances on physiological and ecological effects of cadmium on plants. Acta Ecol. Sin., 20: 514-523.

6. Zhang, J.B., Huang, W.N. (2007) Effects of cadmium stress on photosynthetic functions of strawberry. Chin. J. Appl. Ecol., 18: 1673-1676.

7. Huang, D.F., Wang, Z.Q., Liu, L.J., Yang, C.J. (2010) Effect of cadmium on the rice yield and grain quality. Chin. J. Trop. Crips, 31: 19-24.

8. Wang, J., Wang, X., Lin, L., Liao, M., Liu, J., Tang, Y., Liang, D., Xia, H., Lv, X., Ren, W., Jiang, W. (2019) Effects of different rootstocks on the growth and cadmium-accumulation characteristics of a postgrafting generation of Cyphomandra betacea seedlings. Int. J. Environ. An. Ch., 1-9.

9. Li, H., Wang, J., Lin, L., Liao, M., Lv, X., Tang, Y., Wang, X., Xia, H., Liang, D., Ren, W., Jiang, W. (2019) Effects of mutual grafting on cadmium accumulation characteristics of first post-generations of Bidens pilosa L. and Galinsoga parviflora Cav. Environ. Sci. Pollut. R., 26, 33228-33235.

10. Xia, H., Wang, Y., Liao, M., Lin, L., Zhang, F., Tang, Y., Zhang, H., Wang, J., Liang, D., Deng, Q., Lv, X., Chen, C., Ren, W. (2020) Effects of different rootstocks on cadmium accumulation characteristics of the post-grafting generations of Galinsoga parviflora. Int. J. Phytoremediation, 22: 62-68.

11. Liu, Q., Huo, R., Lin, L., M. Liao, Wang, J., Tang, Y., Liang, D., Xia, H., Lv, X., Ren, W., Jiang, W. (2019) Effects of different rootstocks on cadmium accumulation of grafted Cyphomandra betacea seedlings. Int. J. Environ. An. Ch., 99: 1247-1254.

12. Wu, Y., Geng, S.D., Shi, C.J., Cen, M.L., Wang, X.J., Lian, H.Y. (2014) Effects of DA-6 on growth and leaf nitrogen metabolism of Dendranthema morifolium cv 'chuju' seedlings. Acta Agric. Nucl. Sin., 28, 2283-2289.
13. Poling S.M., Hsu W.J., Yokoyama H. (1982) Synthetic bioregulators of poly-cis carotenoid biosynthesis. Phytochemistry, 21, 601-604.

14. Miao, P.F., Liu, G.J., Li, S.H., Shan, S.M. (2007) Effects of foliar spraying DA-6 on the photosynthetic rate and plant growth of strawberry in autumn. Chin. J. Appl. Ecol., 2722-2726.

15. Yang, Q., Aishajiang, M.M.T., Wang, Z.X., Liu, G.J. (2012) Effects of DA-6 on chlorophyll biosythesis pathway in peach leaves. Acta Hortic. Sin., 17, 621-628.

16. Feng, N.J., Yan, X.F., Zheng, D.F., Liu, B. (2010) Effect of PGRs seed soaking on anatomical strucyure in soybean root. Plant Physiol. Comm., 46: 687-692.

17. Nie, L.X., Jiang, X.Y., Wu, S.H., Zhang, J.W., Liu, P. (2010) Effects of DA-6 on leaf photosynthetic carboxylase and protective enzyme activities and grain yield of high-yielding summer maize. Chin. J. Appl. Ecol., 21, 2558-2564.

18. Ouyang, L.M., Zhang, S.J., Chen, J.F., Li, X., Xu, Y.C. (2010) Effects of different plant growth substances on the growth and root development of water cultured cucumber seedlings. Chin. Agric. Sci. Bull., 26, 161-166.

19. Wang, L., He, S.Y., Li, A.N., Guo, H.H. (2016) MGDA and DA-6 enhanced ryegrass to phytoextract Cd from contaminated soil. J. Soil Water Conserv., 30: $134-140$.

20. Liu, S., Luo, Y.B., Huang, K.L. (2015) Research progress of nutritionally improved transgenic plants. Acta Agric. Nucl. Sin., 29: 337-343.

21. Xue, L., Tian, L.P., Wang, J. (2004) Studies on the law of abbsorption and distribution of nutrient inprocessing tomato under drip irrigation and covering membrane condition. J. Shihezi Univ. (Nat. Sci.), 22: 389-392.

22. Zhang, Y. (2011) Soil, Water, and Plant Physical and Chemical Analysis Course. China Forestry Publishing House, Beijing.

23. Lai, Q.Y., Wei, S.H., Dai, H.P., Jia, G.L. (2019) Response of tomato photosynthetic characteristics and fluorescence parameters of tomato to $\mathrm{Cd}$ in soil. China Environ Sci., 39: 4737-4742.

24. Plaxton W.C., Tran H.T. (2011) Metabolic adaptations of phosphate-starved plants. Plant physiol., 156: 1006-1015.

25. Zhang, E.P., Zhang, S.H., Li, T.L., Ge, X.G. (2005) Advance of research on potassium nutrition. Chin. Agric. Sci. Bull., 21:265-268.

26. Kong, X.S., Lu, W. (2008) Effect of spraying mixture of diethyl aminoethyl hexanoate and chitosan or oligosaccharides on soybean. J. Heilongjiang Aug. First land Re clam. Univ., 20: 1214. 